\title{
Contemporary management of renal trauma in Canada: A 10-year experience at a level 1 trauma centre
}

Uday Mann, MD; Logan Zemp, MD; Keith F. Rourke, MD

Division of Urology, University of Alberta, Edmonton, AB, Canada

Funding: Recipient of the Alberta Health Services Surgery Strategic Clinical Network Summer Surgical Research Studentship (SSRS) Award.

Cite as: Can Urol Assoc J 2018 November 5; Epub ahead of print. http://dx.doi.org/10.5489/cuaj.5581

Published online November 5, 2018

$* * *$

\section{Abstract}

Introduction: Contemporary Canadian renal trauma data is lacking. Our objective is to describe 10-year outcomes of renal trauma at a Canadian level 1 trauma centre using a conservative approach.

Methods: The Alberta Trauma Registry at the University of Alberta was used to identify renal trauma patients from October 2004 to December 2014. Hospital records and imaging were reviewed to identify clinicoradiographical factors, including patient age, gender, Injury Severity Score (ISS), American Association of the Surgery for Trauma (AAST) grade, computerized tomography (CT) findings, urological interventions, length of stay, transfusion and death rates. Descriptive statistics, Chi-square, and t-tests were used when appropriate.

Results: A total of 368 renal trauma patients were identified. Mechanism of injury was blunt trauma in $89.1 \%$ of cases, mean age was 36.2 years, and mean ISS was $30.8( \pm 13.6)$. AAST grade distribution was 16.6\% (Grade I), 22.8\% (Grade II), 36.4\% (Grade III), 20.9\% (Grade IV), and G3.3\% (Grade V). Overall, 9.5\% (35) of patients required urological intervention for a total of 40 treatments, including ureteral stenting (3.0\%), angioembolization (3.3\%), percutaneous drainage $(0.3 \%)$, or open intervention including nephrectomy (2.4\%) and renorraphy $(0.5 \%)$. No Grade 1 or 2 injuries required intervention, while 1.5\%, 31.2\%, and 75.0\% of Grade 3, 4, and 5 injuries did, respectively. The overall renal salvage rate was $97.6 \%$, which did not differ by mechanism of injury $(\mathrm{p}=0.25)$. Patients with penetrating trauma were more likely to require urological intervention (20.0\% vs. 8.2\%; p=0.04). Of the high-grade (III-V) renal injuries identified, 15.7\% (35/223) required urological intervention, 4.9\% (11) required open surgical intervention, and only $4.0 \%$ (9) of patients with high-grade renal injury required nephrectomy. 
Conclusions: The trend towards conservative treatment of renal trauma in Canada appears wellsupported even in a severely injured patient population, as over $90 \%$ of patients avoid urological intervention and only $3 \%$ require operative intervention resulting in renal salvage rates of $97.6 \%$.

\section{Introduction}

Renal trauma is a frequent complication of abdominal trauma, occurring in up to $24 \%$ cases of abdominal trauma. ${ }^{1-3}$ Renal injury is most commonly classified by the AAST-OIS grading system which is based on the degree of damage to the renal parenchymal, urinary collecting system and/or renal vasculature. ${ }^{4}$ Treatment options include conservative treatment, minimally invasive intervention, or open surgical intervention performed either immediately or in a delayed fashion. Observation typically involves bedrest, hemodynamic monitoring, serial lab evaluation and repeat imaging to assess for ongoing hemorrhage or urinary extravasation. If complications arise during conservative management patients typically require intervention either through a minimally invasive or open surgical approach. Minimally invasive therapy is either angioembolization for uncontrolled bleeding or ureteral stent placement, perinephric drain placement, or percutaneous nephrostomy tube for urinary extravasation related to collecting system injury. Open interventions include nephrectomy, partial nephrectomy, renal packing or renorrhaphy. While the AAST-OIS and other clinical/radiographic factors help guide treatment the decision to intervene is ultimately up to the attending surgeon. ${ }^{5-8}$ While some centres employ a lower threshold for operative intervention, over the last 20 years there has been an increasing trend toward conservative treatment of renal injuries related to surgeons' preference as well as advances in imaging and interventional radiologic interventions such as angioembolization and percutaneous access. 9-14 $^{-14}$

Conservative treatment of renal trauma has become the staple of urologic practice in Canada with no contemporary data from Canada to support this trend. ${ }^{15-16}$ Further examination of contemporary Canadian renal trauma data is likely warranted as there exists unique differences between Canadian healthcare delivery and other nations. It is thus likely that the mechanism of injury, demographics, grade and likely treatment of renal trauma differs in Canada from that of other countries. It is our hypothesis that conservative management of renal trauma in Canada has increased in prevalence and has resulted in a reduction in nephrectomy rates even when compared to other developed nations. The main objective of this study was to describe the 10year outcomes of renal trauma at a Canadian level 1 trauma center. A secondary objective was to compare outcomes from blunt trauma versus penetrating trauma during the same time period.

\section{Methods}

The study was a health ethics board approved retrospective review of the Alberta Trauma Registry from October 2004 through December 2014 inclusive. The Alberta Trauma Registry is a repository of trauma information that dates back to April 1, 1995. To qualify for the registry a patient must have an Injury Severity Score (ISS) $\geq 12$, be admitted to a trauma center, or die in 
the emergency department of the trauma center. The database was interrogated for ICD code 866 (kidney injury). All charts and imaging were reviewed by at least 2 of the 3 study investigators to ensure data completeness and accuracy.

\section{Inclusion criteria}

Patients 18 years of age or older with renal trauma and an ISS $\geq 12$ were included in analysis. Patients were excluded if they did not have computerized tomography (CT) imaging available to review. Additionally, patients with incomplete datasets in the Alberta Trauma Registry were excluded.

\section{Patient characteristics}

Hospital records and diagnostic imaging were reviewed to identify the need for urologic intervention related to the renal injury including conservative management, ureteral stenting, percutaneous drainage, angiographic embolization, renorrhaphy or nephrectomy. Clinical, demographic, and radiographic factors examined included patient age, gender, length of stay, Injury Severity Score (ISS), AAST grade, mechanism of trauma, associated injuries, CT findings (laceration length/number, perinephric hematoma, intravascular contrast excretion, devitalized segment status), blood transfusion, and death rates. Urologic intervention was defined as any renal-related intervention and was decided by the individual treating surgeon. Although no specific criteria for intervention were used as a general institutional guideline intervention was performed for uncontrolled bleeding or symptomatic complications arising from collecting system injury.

\section{Statistical analysis}

Descriptive statistics were used to further characterize patient information. Chi-square and t-tests were used when appropriate.

\section{Results}

A total of 487 renal traumas were identified during the study period, of which 368 met study inclusion criteria. Patient demographics, AAST grade and imaging findings are described in Table 1. Of the 368 traumas, $89.1 \%(n=328)$ were due to a blunt mechanism, while the remaining $10.9 \%$ (40) were due to a penetrating mechanism. Mean patient age was 36.2 years and the mean Injury Severity Score (ISS) was $30.8( \pm 13.6)$. AAST grade distribution was Grade I (16.6\%), Grade II (22.8\%), Grade III (36.4\%), Grade IV (20.9\%), and Grade V (3.3\%) with no difference in grade distribution between blunt and penetrating trauma $(p=0.36)$.

When compared to patients with blunt renal trauma, patients with penetrating trauma were more likely to be younger $(p=0.009)$, male $(p=0.002)$, have lower injury severity scores $(\mathrm{p}<0.001)$, have a perinephric hematoma $(\mathrm{p}=0.03)$, have larger perinephric hematomas $(\mathrm{p}=0.01)$, and have intravascular contrast extravasation (ICE) $(p=0.04)$. 97.5\% of all renal trauma patients had associated injuries. The median number of associated injuries in blunt trauma was 9 compared to 5 in penetrating trauma. The most common of these injuries were rib fractures in 
$42.9 \%$ of patients (158/368), injury to the heart and lungs in $30.4 \%$ of patients $(112 / 368)$, and basal skull fractures in $27.7 \%$ of patients (102/368).

Patient outcomes and interventions are outlined in Table 2. A total of $28.3 \%$ of patients required blood transfusion, the mean length of stay was 17.9 days and $5.4 \%$ of patients died as a result of their injuries. Immediate urologic intervention for the renal injury (within 24 hours), was required in $7.6 \%$ of patients (28) while the remaining $92.4 \%$ had initial conservative management of their renal injury which differed between blunt (93.6\%) and penetrating trauma mechanism $(82.5 \%)(\mathrm{p}=0.02)$. Of these 28 patients undergoing immediate intervention, 67.9\% did so for uncontrolled bleeding. Additionally, there was a total of 12 delayed interventions (3.3\%).

Overall, a total of $9.5 \%$ (35) of patients required intervention for renal trauma for a total of 40 treatments including ureteral stenting (3.0\%), angioembolization (3.3\%), percutaneous drainage $(0.3 \%)$ or open intervention including nephrectomy (2.4\%) and renorraphy (0.5\%) (Table 2). Only 3.0\% of patients required open surgical intervention. No grade I or II injuries required intervention while $1.5 \%, 31.2 \%$ and $75.0 \%$ of Grades III, IV and V injuries respectively did. The overall renal salvage rate was $97.6 \%$ which did not differ by mechanism of injury $(\mathrm{p}=0.25)$. However, patients with penetrating trauma were more likely to require urologic intervention (20.0\% vs. 8.2\%; $\mathrm{p}=0.04)$ and had a shorter length of stay $(p=0.03)$. Blood transfusion rates did not differ greatly between the two mechanisms of trauma (blunt $28 \%$ vs penetrating 30\%; $\mathrm{p}=0.8$ ).

Urologic intervention by AAST grade is shown in Figure 3. The 2 grade III injuries that required intervention were caused by penetrating trauma and underwent either angioembolization or open renal exploration with renorrhaphy. Of the high-grade (III-V) renal injuries $15.7 \%$ (35/223) required urologic intervention, 4.9\% (11/223) required open surgical intervention and only $4.0 \%$ (9/223) of patients with high-grade renal injury required nephrectomy.

Mechanisms of both blunt and penetrating trauma are demonstrated in Figure 1. The primary mechanism of blunt trauma was motor vehicle accident, accounting for $52.1 \%$ of blunt trauma. Most of the remaining distribution was car vs pedestrian/cyclist (10.7\%), fall from height (10.1\%), ATV accident (9.1\%), or assault (3.0\%). A large majority (88\%) of penetrating trauma was accounted for by assault by cutting instrument.

\section{Discussion}

Canadian data on renal trauma (especially contemporary data) is lacking. ${ }^{15,16}$ Existing data has become relatively obsolete as it was derived from the era where intravenous pyelograms were still used for trauma staging. Since then, there has been widespread adoption of CT for staging and advances interventional radiology. ${ }^{17}$ Concurrently the AAST grading system has become the standard means to objectively classify renal trauma and guide therapy. Our impression is that conservative management of renal trauma has a long history in Canada but there is minimal Canadian data to support this assumption. Therefore, have presented a contemporary cohort of renal trauma data from a Canadian level 1 trauma centre. 
Patient demographics, trauma mechanism, and grade

The majority of renal trauma in our population was related to a blunt trauma mechanism while $10.9 \%$ were related to penetrating trauma. This is an expected finding and consistent with historical data but is perhaps a somewhat lower rate of penetrating trauma than found in typical urban populations throughout the U.S. and Europe (11-40\%). ${ }^{18}$ In this present series, the majority ( $>80 \%$ ) of blunt trauma were caused by motor vehicle accidents or falls which is consistent with most other studies. ${ }^{2}$ However, over $90 \%$ of the penetrating trauma in our series was due to a cutting instrument whereas $<5 \%$ were due to a firearm. This is in sharp contrast to the U.S. where gunshot wounds account for the majority of penetrating trauma. ${ }^{19}$ Despite some of these key demographic differences our AAST grade distribution is similar to other countries with a $60.6 \%$ rate of high grade injury (grade III-V). ${ }^{14,20}$ Lastly, the mean Injury Severity Score (ISS) of 30.8 was consistent with a severely injured patient population.

Intervention for renal trauma

We have examined interventions and outcomes in this severely injured population of 368 renal trauma patients. Conservative management was well established within our cohort as only 7.6\% patients underwent immediate urologic intervention (most often for uncontrolled bleeding) with a subsequently low rate of (3.3\%) delayed intervention. Ultimately, 90.5\% of our patients were managed conservatively. Although wide variation can exist among different centres, this rate of expectant/conservative management appears higher than that reported in the literature. ${ }^{14,20}$ Recent large U.S. multi-institutional and population database studies show that approximately $80 \%$ of patients undergo conservative treatment. ${ }^{14,20}$ Likewise, stratified by grade of injury our current series demonstrates a trend toward increasing use of conservative treatment in Canada in all but Grade V injuries when compared to the United States (Grade I: 100\% vs. 96\%, Grade II: 100\% vs. $89 \%$, Grade III: $99 \%$ vs. $81 \%$, Grade IV: $68.8 \%$ vs. 55\%, Grade V: $25.0 \%$ vs. $28.5 \%) .{ }^{20}$ Additionally, the rate of open surgical intervention in our cohort was $3.0 \%$. While previous Canadian data showed 7\% rates of renal exploration, more recent large U.S. multiinstitutional and database studies show that $13 \%$ of all renal trauma patients across all grades undergo open surgical intervention. ${ }^{14,16,20}$ Our data emphasizes the emerging trend in expectant management of renal trauma and suggests that Canadian Urologists have enthusiastically embraced this approach.

Ultimately the primary goal of renal trauma treatment is the preservation of renal function. Our series had an overall 97.6\% renal salvage rate despite patients with relatively highgrade injuries and high Injury Severity Scores. This is likely related to a low rate of open renal exploration. Comparison between our Alberta and previously published British Columbia trauma registry data demonstrates lower nephrectomy rates in our contemporary series even when stratified by grade (Grade III: 0\% vs. 13\%, Grade IV: 4\% vs. 17\%, Grade V: 50\% vs. 91\%). ${ }^{16}$ Comparatively in the U.S., contemporary nephrectomy rates also appear to higher, both overall (8.6\%) and when stratified by grade. ${ }^{14}$ Interestingly, McClung et al. reported that nephrectomy was performed across all grades of renal injury and trauma mechanism and 15\% of 
nephrectomies performed were for low grade (grade I or II) injuries. ${ }^{20}$ Most concerning of all was the finding that patients undergoing open exploration had a 64\% rate nephrectomy with very few instances of partial nephrectomy or renorrhaphy. This confirms that when an open operative intervention was performed, it often leads to nephrectomy. It is also possible that improved angioembolization techniques and increasing comfort levels with conservative management have also aided in improved renal salvage rates. ${ }^{21,22}$ However, it is without doubt that our very low nephrectomy rate is at least partly related to a decreased renal exploration rate. Our study aligns with emerging data that using conservative management as a first line therapy reduces nephrectomy rates for all grades of real trauma and is likely the one of the most effective methods to reduce nephrectomy in the setting of trauma. ${ }^{23-25}$

Despite our low rate of renal exploration and subsequently low nephrectomy rate some might argue that high-grade injuries particularly those in hemodynamically unstable patients would better be treated with immediate open surgical exploration. However, contemporary experience from Europe suggests that angioembolization is a highly feasible option in these patients even in the setting of hemodynamically instability. ${ }^{21,22,26}$ Moreover, in our current series, only $4.9 \%$ of patients with high-grade trauma required open surgical intervention and $4.0 \%$ required nephrectomy which is comparatively lower than recent U.S. data where $19 \%$ of highgrade traumas underwent open renal management and 13\% underwent nephrectomy. ${ }^{19}$ Similarly, McClung et al. reported that $27 \%$ of high grade trauma patients underwent intervention and somewhat alarmingly there was a 70.2\% nephrectomy rates in high-grade injuries that underwent open renal exploration. ${ }^{20}$ In our study, renal angioembolization was used in only $5 \%$ of highgrade renal trauma but greater use of conservative treatment combined with selective angioembolization may be the optimal route to decreased nephrectomy rates even in unstable patients with high-grade trauma. ${ }^{27,28}$

Blunt vs. penetrating trauma

In the past, penetrating injuries were believed to be at higher risk for bleeding and have traditionally been treated more aggressively. ${ }^{18,29}$ More recently, selective observation and a nonoperative approach has been shown to be feasible. ${ }^{30}$ In our current series patients with penetrating trauma were more likely to require intervention (20\% vs. $8 \%$ ) but nephrectomy rates remained comparatively low (5\%) and $80 \%$ of patients were still able to be managed conservatively. Patients with penetrating trauma were typically less severely injured but more likely to have a perinephric hematoma, increased hematoma size, and more likely to require angioembolization. Given that the majority of our penetrating renal trauma was caused by a cutting instrument (as opposed to a firearm) this supports emerging evidence that a conservative approach may be appropriate, especially if the mechanism of injury is related to stabbing.

\section{Study limitations}

Our study is limited due to its retrospective nature. Also, there were a number of different urologists practicing over the duration of the study, who likely had differing opinions and 
thresholds for intervention. Although many studies support non-operative management of renal trauma there is still controversy regarding standard indications for intervention. Nonetheless this series represents the "real world" management of renal trauma at a level 1 trauma centre. Additionally, patients were followed in hospital only and we were unable to report long term outcomes after renal trauma which would be valuable in assessing renal function and the presence of hypertension after conservative management. Lastly, the Alberta trauma registry does not capture all variations in managing renal trauma within the province and country.

\section{Conclusion}

This contemporary Canadian study supports the trend towards conservative treatment of renal trauma even in the setting of high-grade trauma and a severely injured patient population. Conservative management is quite possibly the gold standard treatment for the majority of urologists managing renal trauma resulting in low rates of open operative intervention and excellent renal salvage rates. 


\section{References}

1. Wessells H, Suh D, Porter JR, Rivara F, MacKenzie EJ, Jurkovich GJ, et al. Renal injury and operative management in the united states: results of a population-based study. $J$ Trauma 2003; 54: 423-430. doi:10.1097/01.TA.0000051932.28456.

2. Santucci RA, Wessells H, Bartsch G, Descotes J, Heyns CF, McAninch JW, et al. Evaluation and management of renal injuries: consensus statement of the renal trauma subcommittee. BJU Int 2004; 93: 937-54.

3. Paparel P, N'Diaye A, Laumon B, Caillot JL, Perrin P, Ruffion A. The epidemiology of trauma of the genitourinary system after traffic accidents: analysis of a register of over 43,000 victims. BJU Int 2006; 97: 338-341.

4. Moore EE, Shackford SR, Pachter HL, McAninch JW, Browner BD, Champion HR, et al. Organ injury scaling: spleen, liver, and kidney. J Trauma 1989;29:1664-6.

5. Shariat SF, Roehrborn CG, Karakiewicz PI, Dhami G, Stage KH. Evidence-based validation of the predictive value of the American Association for the Surgery of Trauma kidney injury scale. J Trauma 2007 Apr;62(4): 933-9.

6. Nuss GR, Morey AF, Jenkins AC, Pruitt JH, Dugi DD 3rd, Morse B, et al. Radiographic predictors of need for angiographic embolization after traumatic renal injury. J Trauma. 2009 Sep;67(3):578-82. PMID: 19741403

7. Dugi DD, Morey AF, Gupta A, Nuss GR, Sheu GL, Pruitt JH. American Association for the Surgery of Trauma grade 4 renal injury substratification into grades 4a (Low Risk) and 4b (High Risk). J Urol 2010; 183:592-7.

8. Zemp L, Mann U and Rourke KF: Perinephric hematoma size is independently associated with the need for urological intervention in multisystem blunt renal trauma. J Urol. 2018 May;199(5):1283-88.

9. Santucci RA, Fisher MB: The literature increasingly supports expectant (conservative) management of renal trauma--a systematic review. J Trauma 2005; 59: 493-503.

10. McGuire J, Bultitude MF, Davis P, Koukounaras J, Royce PL, Corcoran NM. Predictors of outcome for blunt high grade renal injury treated with conservative intent. J Urol 2011; 185: 187-191.

11. Long JA, Fiard G, Descotes JL, Arnoux V, Arvin-Berod A, Terrier N. High-grade renal injury: non-operative management of urinary extravasation and prediction of long-term outcomes. BJU Int 2012; 111: E249-E255.

12. Prasad NH, Devraj R, Chandriah GR, Sagar SV, Reddy ChR, Murthy PV. Predictors of nephrectomy in high grade blunt renal trauma patients treated primarily with conservative intent. Indian J Urol 2014; 30: 158.

13. Maarouf AM, Ahmed AF, Shalaby E, Badran Y, Salema E, Zaiton F. Factors predicting the outcome of non-operative management of high-grade blunt renal trauma. Afr J Urol 2015; 21: 44-51. 
14. Hotaling JM, Wang J, Sorensen MD, Rivara FP, Gore JL, Jurkovich J, et al. A national study of trauma level designation and renal trauma outcomes. J Urol 2012; 187:536-41.

15. Herschorn S, Radomski SB, Shoskes DA, Mahoney J, Hirshberg E, Klotz L. Evaluation and treatment of blunt renal trauma. J Urol 1991; 146: 274-276.

16. Baverstock R, Simons R, McLoughlin M: Severe blunt renal trauma: a 7-year retrospective review from a provincial trauma centre. Can J Urol 2001; 8:1372-1376.

17. Hurtuk M, Reed RL, Esposito TJ, Davis KA, Luchette FA. Trauma surgeons practice what they preach. The NTDB story on solid organ injury management. J Trauma 2006 Aug;61(2):243-54;discussion 254-255.

18. Kansas BT, Eddy MJ, Mydlo JH, Uzzo RG. Incidence and management of penetrating renal trauma in patients with multiorgan injury: extended experience at an inner city trauma center. J Urol 2004 Oct;172(4Pt1):1355-60.

19. Keihani S, Yizhe Xu, Presson AP, Hotaling J, Nirula R, Piotrowski J, et al. Contemporary management of high-grade renal trauma: Results from the American Association for the Surgery of Trauma Genitourinary Trauma study. J Trauma Acute Care Surg. 2018;84: 418-425.

20. McClung CD, Hotaling JM, Wang J, Wessells H, Voelzke BB. Contemporary trends in the immediate surgical management of renal trauma using a national database. $J$ Trauma Acute Care Surg. 2013;75(4):602-606.

21. Lanchon C, Fiard G, Arnoux V, Descotes JL, Rambeaud JJ, Terrier N, et al. High grade blunt renal trauma: predictors of surgery and long-term outcomes of conservative management. a prospective single center study. J Urol. 2016;195(1):106-111.

22. Muller A, Rouviere O. Renal artery embolization-indications, technical approaches and outcomes. Nat Rev Nephrol. 2015;11(5):288-301.

23. Hammer CC, Santucci RA. Effect of an institutional policy of nonoperative treatment of grades I to IV renal injuries. J Urol 2003;169(5):1751-3.

24. Robert M, Drianno N, Muir G, Delbos O, Guiter J. Management of major blunt renal lacerations: surgical or nonoperative approach? Eur Urol 1996;30(3):335-9.

25. Danuser H, Wille S, Zöscher G, Studer U. How to treat blunt kidney ruptures: primary open surgery or conservative treatment with deferred surgery when necessary? Eur Urol 2001;39(1):9-14.

26. Charbit J, Manzanera J, Millet I, Roustan JP, Chardon P, Taourel P, et al. What are the specific computed tomography scan criteria that can predict or exclude the need for renal angioembolization after high-grade renal trauma in a conservative management strategy? J Trauma. 2011;70(5):1219-27.

27. Hotaling JM, Sorensen MD, Smith TG 3rd, Rivara FP, Wessells H, Voelzke BB. Analysis of diagnostic angiography and angioembolization in the acute management of renal trauma using a national data set. J Urol 2011;185(4):1316-20. 
28. Sugihara T, Yasunaga H, Horiguchi H, Nishimatsu H, Fukuhara H, Enomoto Y, et al. Management trends, angioembolization performance and multiorgan injury indicators of renal trauma from Japanese administrative claims database. Int J Urol 2012;19(6):55963.

29. Zinman LN, Vanni AJ. Surgical management of urologic trauma and iatrogenic injuries. Surg Clin North Am. 2016;96(3):425-39.

30. Navsaria PH, Nicol AJ, Edu S, Gandhi R, Ball CG. Selective nonoperative management in 1106 patients with abdominal gunshot wounds: conclusions on safety, efficacy, and the role of selective CT imaging in a prospective single-center study. Ann Surg. 2015;261(4):760-64. 
Figures and Tables

Fig. 1. Specific cause of renal trauma for both $(\boldsymbol{A})$ blunt and $(\boldsymbol{B})$ penetrating trauma mechanisms

A.

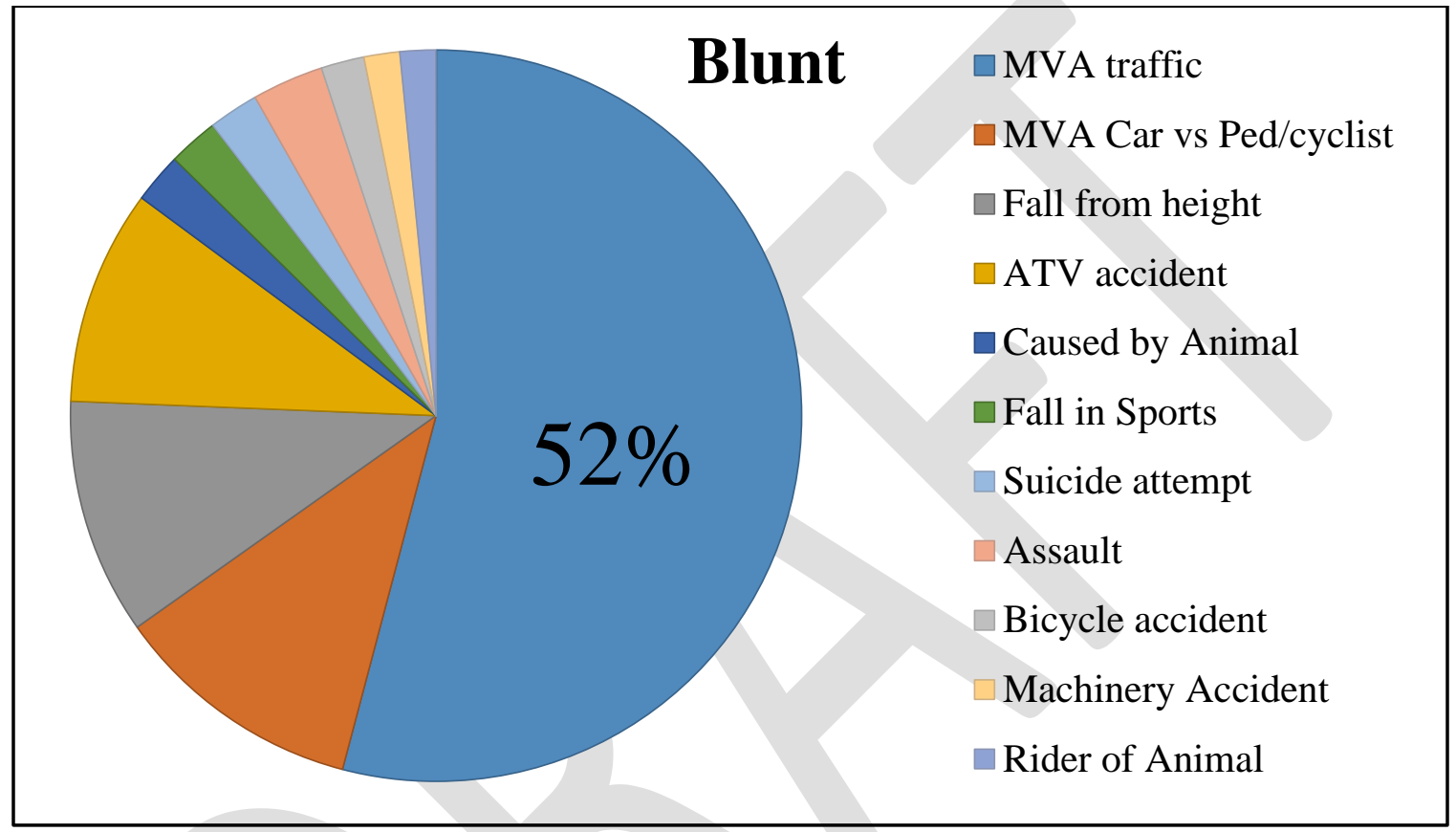


B.

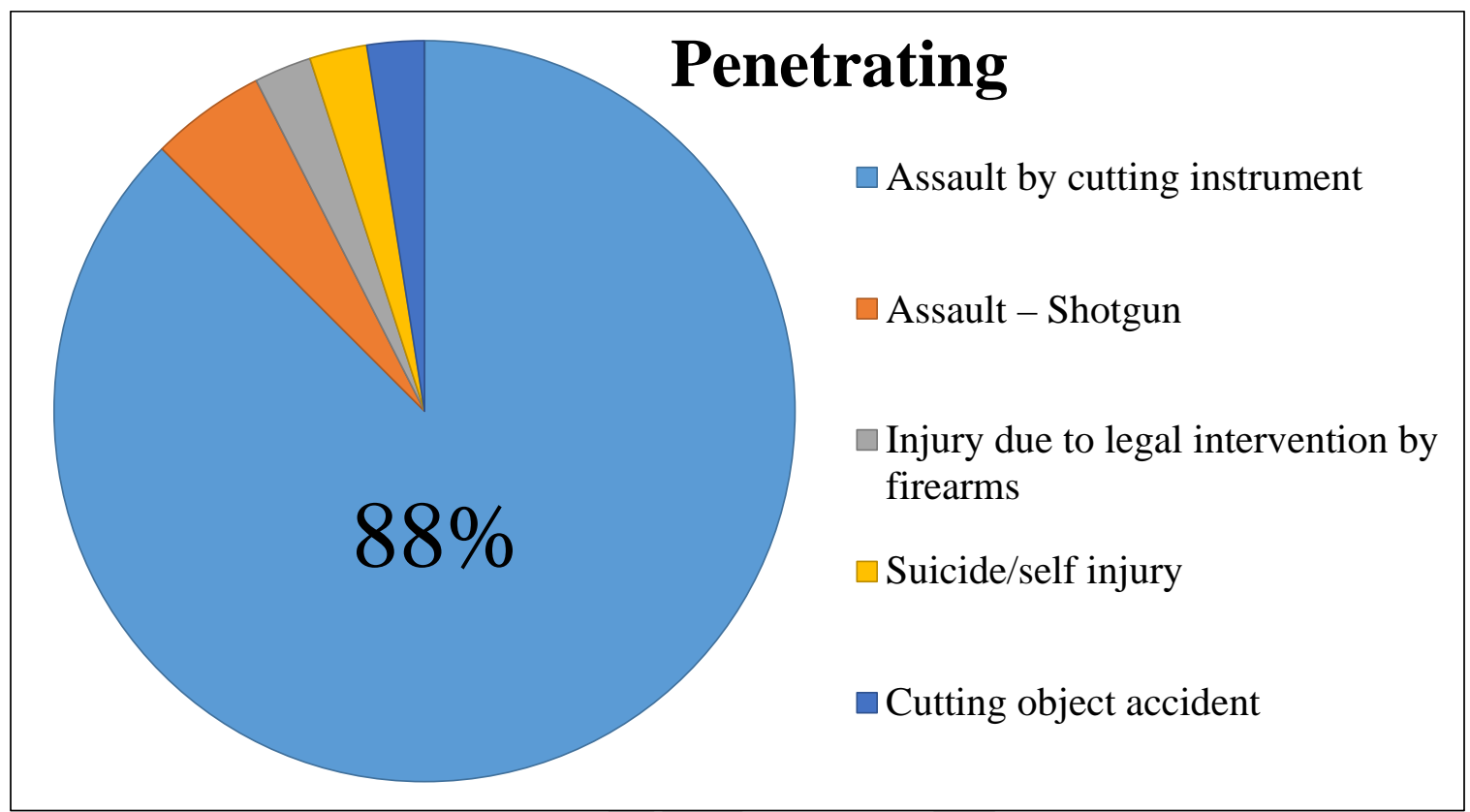


Table 1. Patient demographics, grade of injury, and imaging findings for the overall cohort and classified by both blunt and penetrating trauma

\begin{tabular}{|l|c|c|c|c|}
\hline & Overall (\%) & Blunt (\%) & Penetrating (\%) & p \\
\hline $\mathrm{n}$ & 368 & $328(89.1 \%)$ & $40(10.9 \%)$ & \\
\hline Age & $36.2 \pm 16.7$ & $37.0 \pm 17(17-86)$ & $29.8 \pm 10(18-61)$ & $\mathbf{0 . 0 0 9}^{*}$ \\
\hline Gender & & & & \\
\hline Male & $299(81.3 \%)$ & $260(79.3 \%)$ & $39(97.5 \%)$ & $\mathbf{0 . 0 0 2}^{*}$ \\
\hline Female & $69(18.8 \%)$ & $68(20.7 \%)$ & $1(2.5 \%)$ & \\
\hline $\begin{array}{l}\text { Injury Severity } \\
\text { Score (ISS) }\end{array}$ & $30.8 \pm 13.6$ & $31.7 \pm 13.9$ & $23.7 \pm 9.1$ & $<\mathbf{0 . 0 0 1}^{*}$ \\
\hline AAST grade & & & & \\
\hline \multicolumn{1}{|c|}{ I } & $61(16.6 \%)$ & $58(17.7 \%)$ & $3(7.5 \%)$ & 0.36 \\
\hline \multicolumn{1}{|c|}{ II } & $84(22.8 \%)$ & $76(23.2 \%)$ & $8(20.0 \%)$ & \\
\hline \multicolumn{1}{|l}{ IV } & $134(36.4 \%)$ & $118(36.0 \%)$ & $16(40.0 \%)$ & \\
\hline \multicolumn{1}{|l}{ V } & $77(20.9 \%)$ & $65(19.8 \%)$ & $12(30.0 \%)$ & \\
\hline $\begin{array}{l}\text { Perinephric } \\
\text { hematoma }\end{array}$ & $12(3.3 \%)$ & $11(3.4 \%)$ & $1(2.5 \%)$ & \\
\hline $\begin{array}{l}\text { Hematoma diameter, } \\
\text { cm }\end{array}$ & $403(82.3 \%)$ & $265(80.8 \%)$ & $38(95.0 \%)$ & $\mathbf{0 . 0 3}{ }^{*}$ \\
\hline $\begin{array}{l}\text { Laceration length, } \\
\text { cm }\end{array}$ & $1.2 \pm 1.1$ & $1.2 \pm 1.1$ & $1.5 \pm 1.0$ & 0.06 \\
\hline ICE & $8 / 368(2.2 \%)$ & $5 / 328(1.5 \%)$ & $3 / 40(7.5 \%)$ & $\mathbf{0 . 0 4}^{*}$ \\
\hline $\begin{array}{l}\text { Devitalized } \\
\text { fragment }\end{array}$ & $88 / 368(23.9 \%)$ & $79 / 328(24.1 \%)$ & $9 / 40(22.5 \%)$ & 0.50 \\
\hline
\end{tabular}

${ }^{*} \mathrm{p}<0.05$. AAST: American Association of the Surgery for Trauma; ICE: intravascular contrast extravasation. 


\begin{tabular}{|c|c|c|c|c|}
\hline & Overall & Blunt & Penetrating & $\mathbf{p}$ \\
\hline Patients & 368 & 328 & 40 & \\
\hline Transfusion & $104(28.3 \%)$ & $92(28.0 \%)$ & $12(30.0 \%)$ & 0.85 \\
\hline Length of stay, days & $17.9 \pm 23.5$ & $19 \pm 24(0-243)$ & $10 \pm 12(0-44)$ & $0.03^{*}$ \\
\hline Death & $20(5.4 \%)$ & $19(5.8 \%)$ & $1(2.5 \%)$ & 0.71 \\
\hline Immediate treatment & $28(7.6 \%)$ & $21(6.4 \%)$ & $7(17.5 \%)$ & $0.02^{*}$ \\
\hline Delayed treatment & $12(3.3 \%)$ & $10(3.0 \%)$ & $2(5.0 \%)$ & 0.63 \\
\hline $\begin{array}{l}\text { Patients requiring } \\
\text { urological } \\
\text { intervention }\end{array}$ & $35(9.5 \%)$ & $27(8.2 \%)$ & $8(20.0 \%)$ & $0.04^{*}$ \\
\hline \multicolumn{5}{|l|}{ Type of intervention } \\
\hline Ureteral stent & $11(3.0 \%)$ & $10(3.0 \%)$ & $1(2.5 \%)$ & 1.0 \\
\hline Angioembolization & $12(3.3 \%)$ & $8(2.4 \%)$ & $4(10.0 \%)$ & $0.03^{*}$ \\
\hline Nephrectomy & $9(2.4 \%)$ & $7(2.1 \%)$ & $2(5.0 \%)$ & 0.25 \\
\hline Renorraphy & $2(0.5 \%)$ & $1(0.3 \%)$ & $1(2.5 \%)$ & 0.21 \\
\hline Percutaneous drain & $1(0.3 \%)$ & $1(0.3 \%)$ & $0(0 \%)$ & \\
\hline Renal salvage rate & $359(97.6 \%)$ & $321(97.9 \%)$ & $38(95.5 \%)$ & 0.25 \\
\hline $\begin{array}{l}\text { Intervention by AAST } \\
\text { grade }\end{array}$ & & & ) & 1.0 \\
\hline $\mathrm{I}$ & $0 / 61(0 \%)$ & $0 / 58(0 \%)$ & $0 / 3(0 \%)$ & 1.0 \\
\hline II & $0 / 84(0 \%)$ & $0 / 76(0 \%)$ & $0 / 8(0 \%)$ & 1.0 \\
\hline III & $2 / 134(1.5 \%)$ & $0 / 118(0 \%)$ & $2 / 16(12.5 \%)$ & $0.01^{*}$ \\
\hline IV & $24 / 77(31.2 \%)$ & 19/65 (29.2\%) & $5 / 12(41.7 \%)$ & 0.50 \\
\hline 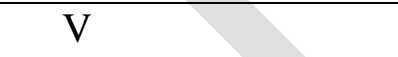 & 9/12 (75.0\%) & 8/11 (72.7\%) & 1/1 (100\%) & 1.0 \\
\hline $\mathrm{p}$ for AAST grade & $<0.0001$ & $<0.0001$ & 0.02 & \\
\hline
\end{tabular}

$\mathrm{p}<0.05$. AAST: American Association of the Surgery for Trauma. 
10-year experience with renal trauma at level 1 trauma centre

\section{Table 3. Urological intervention for renal trauma stratified by AAST grade}

\begin{tabular}{|l|c|c|c|c|c|c|}
\hline $\begin{array}{l}\text { AAST } \\
\text { grade }\end{array}$ & Conservative & $\begin{array}{c}\text { Ureteral } \\
\text { stent }\end{array}$ & $\begin{array}{c}\text { Angio- } \\
\text { embolization }\end{array}$ & Nephrectomy & Renorraphy & $\begin{array}{c}\text { Percutaneous } \\
\text { drain }\end{array}$ \\
\hline I & $61 / 61(100 \%)$ & $0 / 61(0 \%)$ & $0 / 61(0 \%)$ & $0 / 61(0 \%)$ & $0 / 61(0 \%)$ & $0 / 61(0 \%)$ \\
\hline II & $84 / 84(100 \%)$ & $0 / 84(0 \%)$ & $0 / 84(0 \%)$ & $0 / 84(0 \%)$ & $0 / 84(0 \%)$ & $0 / 84(0 \%)$ \\
\hline III & $\begin{array}{l}132 / 134 \\
(98.5 \%)\end{array}$ & $0 / 134(0 \%)$ & $1 / 134(0.7 \%)$ & $0 / 134(0 \%)$ & $1 / 134(0.7 \%)$ & $0 / 132(0 \%)$ \\
\hline IV & $53 / 77(68.8 \%)$ & $11 / 77$ & $8 / 77(10.4 \%)$ & $3 / 77(3.9 \%)$ & $1 / 77(1.3 \%)$ & $1 / 77(1.3 \%)$ \\
\hline V & $3 / 12(25.0 \%)$ & $0 / 12(0 \%)$ & $3 / 12(25.0 \%)$ & $6 / 12(50.0 \%)$ & $0 / 12(0 \%)$ & $0 / 12(0 \%)$ \\
\hline
\end{tabular}

AAST grade was strongly associated with the need for urological intervention $(\mathrm{p}<0.0001)$. AAST:

American Association of the Surgery for Trauma. 